\title{
Joint Residence-Workplace Location Choice Model Based on Household Decision Behavior
}

\author{
Pengpeng Jiao, ${ }^{1}$ Tuo Sun, ${ }^{1}$ Jin Guo, $^{2}$ and Yangwei $\mathrm{Li}^{1}$ \\ ${ }^{1}$ School of Civil and Transportation Engineering, Beijing University of Civil Engineering and Architecture, Beijing 100044, China \\ ${ }^{2}$ China Patent Information Center, Beijing 100088, China
}

Correspondence should be addressed to Pengpeng Jiao; jiaopengpeng@bucea.edu.cn

Received 11 July 2014; Accepted 26 August 2014

Academic Editor: Geert Wets

Copyright (c) 2015 Pengpeng Jiao et al. This is an open access article distributed under the Creative Commons Attribution License, which permits unrestricted use, distribution, and reproduction in any medium, provided the original work is properly cited.

\begin{abstract}
Residence location and workplace are the two most important urban land-use types, and there exist strong interdependences between them. Existing researches often assume that one choice dimension is correlated to the other. Using the mixed logit framework, three groups of choice models are developed to illustrate such choice dependencies. First, for all households, this paper presents a basic methodology of the residence location and workplace choice without decision sequence based on the assumption that the two choice behaviors are independent of each other. Second, the paper clusters all households into two groups, choosing residence or workplace first, and formulates the residence location and workplace choice models under the constraint of decision sequence. Third, this paper combines the residence location and workplace together as the choice alternative and puts forward the joint choice model. A questionnaire survey is implemented in Beijing city to collect the data of 1994 households. Estimation results indicate that the joint choice model fits the data significantly better, and the elasticity effects analyses show that the joint choice model reflects the influences of relevant factors to the choice probability well and leads to the job-housing balance.
\end{abstract}

\section{Introduction}

Integrated land-use and transportation models are most important for both urban planning and transportation planning, and many researches have explored the interdependences between land-use and transportation systems. In the urban land-use pattern, one most important type is residence location, as well as the workplace. These two landuse types influence households' trip pattern greatly. Based on the personal trip survey (PT survey) data of more than 10 Chinese cities, such as Beijing, Shanghai, and Dalian, more than eighty percent of household daily trips are commute trips; that is, these trips depart from residence location and are directed to workplace, or vice versa. Therefore, it is very important to reveal the inherent mechanism of residence location and workplace choice behavior, especially for fast developing Chinese cities.

As an important behavior analysis approach, discrete choice model has been extensively used in the location choice researches. Lerman [1] and McFadden [2] have formulated residential location choice models using discrete choice method more than 30 years ago. Based on the above pioneering researches, Timmermans et al. [3], Waddell [4], Waddell [5], Ben-Akiva and Bowman [6], Sermons and Koppelman [7], Sermons [8], and Sermons and Koppelman [9] have further developed many models to describe households' residence location choices using discrete choice approaches too.

In more recent years, Bhat and Guo [10], Miyamoto et al. [11], Bhat and Guo [12], Guo and Bhat [13], and Jiao and Harata [14] have also proposed several residential location choice models using different discrete choice methods. Bhat and Guo [10] put forward a mixed logit model to analyze the residential location choice behavior and considered random taste variations in their model, as well as the spatial correlations among different residential locations. Miyamoto et al. [11] also proposed a residential location choice model using mixed logit method and used a stochastic process to formulate the spatial correlation. Bhat and Guo [12] formulated a joint mixed multinomial logit-ordered model to present the residential sorting effects and applied it to comprehensively examine the impact of 
the built environment, transportation network attributes, and demographic characteristics on residential choice and car ownership decisions. Guo and Bhat [13] explored different conceptualizations to represent neighborhoods in residential location choice models and described three alternative ways to construct operational units to represent neighborhoods. Jiao and Harata [14] presented a mixed logit framework to identify residential location choice behavior in different households and integrated a "direct parametric representation" approach to capture the correlation between spatial units, as well as a comprehensive structure of zonal accessibility to reflect the effects of employment, school, shopping, and recreational opportunities. Most recently, $\mathrm{Li}$ et al. [15] formulated a multiobjective optimization model to distribute residential spatial units integrating three objectives. All the above models obtained rather significant results.

As for workplace choice, it has also been extensively studied using similar methods in the framework of disaggregated travel models, for example, Abraham and Hunt [16] and Levine [17].

Most above models of residence location or workplace choice often assume that one choice dimension is exogenous to the other; that is, residence location choice is conditional on predetermined workplace, or vice versa. However, there exist strong interdependences between residence and workplace locations, and such kinds of interdependences have been studied in several existing researches. Waddell [4] questioned it through an empirical study using data of the metropolitan area of Dallas-Fort Worth (Texas, USA). Waddell et al. [18] developed a discrete choice model of joint residence location and workplace choice using methods of latent market segmentation for one-worker households and put forward a methodology for accommodating different sequential decision-making processes. Li et al. [19] also formulated a joint decision model of residence location and workplace using nested logit method and applied it to Beijing city. Ibeas et al. [20] specified a nested logit model and a cross-nested logit model to investigate the existence of spatial correlation between residence and workplace locations and found out that the inclusion of spatial correlations in the model fits the data significantly better.

To revise the residence location and workplace choice models with the assumption that residential location and workplace are chosen independently of each other, that is, without decision sequence, one key feature of this paper is to cluster the households into two groups, choosing residence location first and choosing workplace first, and to formulate the residence location and workplace choice models under the constraint of decision sequence. Another key feature is to further combine the residence location and workplace together and to present the joint choice model.

The rest of this paper is organized as follows. The basic models for all households without decision sequence are proposed in Section 2. Clustering households into two groups, the revised models with decision sequence are presented in Section 3. The joint residence-workplace location choice model is put forward in Section 4 based on the combined choice alternatives. A questionnaire survey is implemented, and the data is illustrated in Section 5. The estimation results of three groups of models are reported and compared in Section 6, as well as the elasticity effects analyses. Conclusions and further researches are summarized in the last section.

\section{Residence Location and Workplace Choices without Decision Sequence}

In this section, the residence location and workplace choices are assumed to be independent of each other.

2.1. Residence Location Choice without Decision Sequence. Essentially, the household decision behavior influences the residential location choice greatly. Using the discrete choice method, the random utility theory is employed to describe such decision behavior. The following equation is formulated to indicate whether a household will choose a location as the residence place or not:

$$
I_{h i}= \begin{cases}\text { one } & \text { if } U_{h i} \geq U_{h j} \text { for } j=1, \ldots, K \\ \text { zero } & \text { otherwise, }\end{cases}
$$

where $I_{h i}$ is an indicator to denote whether household $h$ selects spatial unit $i$ to reside or not; $U_{h i}$ is the utility for household $h$ to select spatial unit $i$; $K$ is the total number of spatial units in the choice set.

Usually, the utility function $U_{h i}$ may be divided into two items: the systematic item $V_{h i}$ and the random item $\varepsilon_{h i}$ :

$$
U_{h i}=V_{h i}+\varepsilon_{h i}
$$

In a mixed logit formulation, the deterministic term $V_{h i}$ can be further represented as below:

$$
V_{h i}=\sum_{m=1}^{M} \alpha_{m} z_{h i m}+\sum_{n=1}^{N} \theta_{n} x_{h i n}
$$

where $\alpha_{m}$ and $\theta_{n}$ are parameters to be estimated, $\alpha_{m}$ is the fixed parameter, $\theta_{n}$ is the unfixed parameter subject to a logarithmic normal distribution; $z_{\text {him }}$ and $x_{\text {hin }}$ are explanatory variables, for example, spatial unit information, household information, travel related information, and so forth; $M$ is the number of explanatory variables corresponding to the fixed parameters; $N$ is the number of explanatory variables corresponding to the unfixed parameters.

Based on the above formulations, the choice probability for household $h$ to choose spatial unit $i$ is presented as a mixed logit formulation:

$$
\begin{aligned}
L_{h i} & =\frac{\exp \left(V_{h i}\right)}{\sum_{j=1}^{K} \exp \left(V_{h j}\right)} \\
& =\frac{\exp \left(\sum_{m=1}^{M} \alpha_{m} z_{h i m}+\sum_{n=1}^{N} \theta_{n} x_{h i n}\right)}{\sum_{j=1}^{K} \exp \left(\sum_{m=1}^{M} \alpha_{m} z_{h j m}+\sum_{n=1}^{N} \theta_{n} x_{h j n}\right)} .
\end{aligned}
$$

Using $f(\cdot)$ to represent the density function of the logarithmic normal distribution, the unconditional choice 
probability for household $h$ to choose spatial unit $i$ is therefore the integral of $L_{h i}$ over all possible variables of $\theta_{n}$ :

$$
\begin{aligned}
P_{h i}=\int_{-\infty}^{\infty} & {\left[\frac{\exp \left(\sum_{m=1}^{M} \alpha_{m} z_{h i m}+\sum_{n=1}^{N} \theta_{n} x_{h i n}\right)}{\sum_{j=1}^{K} \exp \left(\sum_{m=1}^{M} \alpha_{m} z_{h j m}+\sum_{n=1}^{N} \theta_{n} x_{h j n}\right)}\right] } \\
& \cdot f(\theta) d \theta .
\end{aligned}
$$

According to the factors households pay most attention to when they make the residence location choice, the explanatory variables include the following:

$\mathrm{TT}_{i}$ : household travel time between residence location and workplace;

$\mathrm{TD}_{i}$ : household travel distance between residence location and workplace;

$\mathrm{TC}_{i}$ : household travel cost between residence location and workplace;

$\mathrm{HP}_{i}$ : regional housing price around residence location;

$\mathrm{PO}_{i}$ : regional population around residence location;

$\mathrm{ZD}_{i}$ : number of regional rail transit stations around residence location;

$\mathrm{FAR}_{i}$ : regional floor area ratio (FAR) around residence location.

According to several estimation experiments, $\mathrm{TT}_{i}$ and $\mathrm{TD}_{i}$ are assumed to be corresponding to the unfixed parameters $\theta_{n}$.

Therefore, (5) can be further represented as

$$
\begin{aligned}
& P_{h i}=\int_{-\infty}^{\infty}\left[\left(\operatorname { e x p } \left(\theta_{1} \mathrm{TT}_{i}+\theta_{2} \mathrm{TD}_{i}+\alpha_{1} \mathrm{TC}_{i}+\alpha_{2} \mathrm{HP}_{i}\right.\right.\right. \\
& \left.\left.+\alpha_{3} \mathrm{PO}_{i}+\alpha_{4} \mathrm{ZD}_{i}+\alpha_{5} \mathrm{FAR}_{i}\right)\right) \\
& \times\left(\sum _ { j = 1 } ^ { K } \operatorname { e x p } \left(\theta_{1} \mathrm{TT}_{j}+\theta_{2} \mathrm{TD}_{j}+\alpha_{1} \mathrm{TC}_{j}\right.\right. \\
& +\alpha_{2} \mathrm{HP}_{j}+\alpha_{3} \mathrm{PO}_{j} \\
& \left.\left.\left.+\alpha_{4} \mathrm{ZD}_{j}+\alpha_{5} \mathrm{FAR}_{j}\right)\right)^{-1}\right]
\end{aligned}
$$

$$
f(\theta) d \theta
$$

In this model, the unfixed parameter $\theta_{n}$ is assumed to follow the following logarithmic normal distribution:

$$
\theta_{n}\left(s_{k}, \xi_{n}, \eta_{n}\right)=\frac{1}{2 \sqrt{\pi} \eta_{n}} \exp \left[-\left(\frac{\ln \left(s_{k}\right)-\xi_{n}}{\eta_{n}}\right)^{2}\right],
$$

where $s_{k}$ is the random variable, and $\xi_{n}$ and $\eta_{n}$ are the expectation and variance of $\ln \left(s_{k}\right)$, respectively.
2.2. Workplace Choice without Decision Sequence. Similar to the residence location choice model, the mixed logit method is employed to model the workplace choice.

According to the factors households pay most attention to when they make the workplace choice, the explanatory variables include household travel time $\mathrm{TT}_{i}$, household travel distance $\mathrm{TD}_{i}$, household travel cost $\mathrm{TC}_{i}$, and

$\mathrm{INC}_{i}$ : household annual income;

$\mathrm{EMP}_{i}$ : number of regional employment opportunities around workplace;

$\mathrm{GS}_{i}$ : regional gross sale of consumer goods around workplace.

Based on several estimation experiments, $\mathrm{TT}_{i}$ and $\mathrm{TD}_{i}$ are also assumed to be corresponding to the unfixed parameters $\theta_{n}$.

Therefore, the workplace choice model without decision sequence is represented as

$$
\begin{aligned}
& P_{h i}=\int_{-\infty}^{\infty}[\left(\operatorname { e x p } \left(\theta_{1} \mathrm{TT}_{i}+\theta_{2} \mathrm{TD}_{i}+\alpha_{1} \mathrm{TC}_{i}\right.\right. \\
&\left.\left.+\alpha_{2} \mathrm{INC}_{i}+\alpha_{3} \mathrm{EMP}_{i}+\alpha_{4} \mathrm{GS}_{i}\right)\right) \\
& \times\left(\sum _ { j = 1 } ^ { K } \operatorname { e x p } \left(\theta_{1} \mathrm{TT}_{j}+\theta_{2} \mathrm{TD}_{j}+\alpha_{1} \mathrm{TC}_{j}+\alpha_{2} \mathrm{INC}_{j}\right.\right. \\
&\left.\left.\left.+\alpha_{3} \mathrm{EMP}_{j}+\alpha_{4} \mathrm{GS}_{j}\right)\right)^{-1}\right]
\end{aligned}
$$$$
\cdot f(\theta) d \theta
$$

In this model, the unfixed parameters $\theta_{1}$ and $\theta_{2}$ are also assumed to follow the logarithmic normal distribution as shown in (7).

\section{Residence Location and Workplace Choices with Decision Sequence}

In the above two models, we assume that residence location choice and workplace choice are independent of each other; that is, people choose locations without decision sequence. However, some households tend to choose workplace first and then choose residence location according to the constraint of workplace, or vice versa. Both of these sequential choice processes are present in the population in a proportion that is unknown to the analyst. Fortunately, the cluster analysis provides an effective method to differentiate them. In this section, we relieve the strong assumption, cluster all households into two groups, and formulate the residence location and workplace choice models with decision sequence.

In this research, a large amount of information about the households is collected through a questionnaire survey, and seven groups of preference data are extracted to represent 
the households' preferences when they choose residence and workplace locations, including the following:

(1) residence location is adjacent to workplace;

(2) traffic is convenient;

(3) commute is convenient;

(4) housing price is acceptable;

(5) there are good schools nearby;

(6) geographic position is good;

(7) residential community environment is excellent.

Based on the above 7 groups of preference data, cluster analysis is then implemented to cluster all households into two categories, choosing workplace first, and then choosing residence location conditional on workplace, or vice versa. The detailed data and clustering results are described in Section 5 .

Using survey data of clustered households, we can formulate the residence location and workplace choice models with decision sequence, respectively. For the convenience of comparison between different models, we use the same explanatory variables here as models without decision sequence. Therefore, the residence location choice model with decision sequence is the same as (6), while the workplace choice model with decision sequence is the same as (8). Here the unfixed parameters $\theta_{1}$ and $\theta_{2}$ are also assumed to follow the logarithmic normal distribution as shown in (7).

\section{Joint Residence-Workplace Location Choice}

As stated above, there exist strong interdependences between residence and workplace locations, and in most time they influence each other, and households tend to consider these two choice problems together. It is often unreasonable to simply assume that households choose residence location or workplace first. Therefore, we assume that both residence location and workplace choices are made simultaneously as an instantaneous bundle and then model the interdependence based on such assumption.

In this model, we take the residence-workplace location pairs as new choice alternatives. To model the joint location choice behavior, all explanatory variables influencing residence location and workplace choices are incorporated within the joint choice model

$$
\begin{aligned}
P_{h i}=\int_{-\infty}^{\infty}[(\exp & \theta_{1} \mathrm{TT}_{i}+\theta_{2} \mathrm{TD}_{i}+\alpha_{1} \mathrm{TC}_{i}+\alpha_{2} \mathrm{HP}_{i} \\
& +\alpha_{3} \mathrm{PO}_{i}+\alpha_{4} \mathrm{ZD}_{i} \\
& \left.\left.+\alpha_{5} \mathrm{FAR}_{i}+\alpha_{6} \mathrm{INC}_{i}+\alpha_{7} \mathrm{EMP}_{i}+\alpha_{8} \mathrm{GS}_{i}\right)\right)
\end{aligned}
$$

$$
\begin{aligned}
\times\left(\sum_{j=1}^{K} \exp (\right. & \theta_{1} \mathrm{TT}_{j}+\theta_{2} \mathrm{TD}_{j}+\alpha_{1} \mathrm{TC}_{j}+\alpha_{2} \mathrm{HP}_{j} \\
& +\alpha_{3} \mathrm{PO}_{j}+\alpha_{4} \mathrm{ZD}_{j} \\
& +\alpha_{5} \mathrm{FAR}_{j}+\alpha_{6} \mathrm{INC}_{j} \\
& \left.\left.\left.+\alpha_{7} \mathrm{EMP}_{j}+\alpha_{8} \mathrm{GS}_{j}\right)\right)^{-1}\right]
\end{aligned}
$$

$\cdot f(\theta) d \theta$.

The definitions of all variables in (9) are the same as the above, and the unfixed parameters $\theta_{1}$ and $\theta_{2}$ are also assumed to follow the logarithmic normal distribution as shown in (7). Since the residence-workplace location pairs are taken as the choice alternatives, the number of alternatives increases dramatically.

\section{Data}

To testify the above three groups of models, we collected the field data of 1994 households in Beijing city through a questionnaire survey. The residence and workplace locations in the data cover all districts of Beijing city, including 6 urban districts and 10 suburban districts.

Table 1 provides a summary of household characteristics in the survey data used, and the distributions of household structure, household income, car ownership, and commuting mode are included. The clustered result of households choosing residence or workplace first is also shown in the table.

From Table 1 we can find out that now more than 60\% of Chinese households in Beijing own one or more cars. The rail transit and bus modes are clearly the superior modes of transport structure in this case study.

Furthermore, for estimation of models with decision sequence, all 1994 households were clustered into two groups using the cluster analysis method based on 7 kinds of preferences in Section 3. The clustering results are also shown at the bottom of Table 1 .

In addition to the questionnaire survey data, three other data sets associated with Beijing city were used: land use data, demographic data, and census data. The land use data was obtained from Beijing Municipal Commission of Urban Planning and was used to get the acreage of each residence and workplace location. The demographic data and census data came from Beijing Municipal Bureau of Statistics and were used to compute the regional housing price, regional population, number of regional rail transit stations, regional floor area ratio (FAR), household income, number of regional employment opportunities, and regional gross sale of consumer goods for each residence location or workplace.

All the above data provide a rich set of variables for consideration in model specification. 
TABLE 1: Household characteristics of the survey sample.

\begin{tabular}{|c|c|c|}
\hline Characteristic & $\begin{array}{l}\text { Number of } \\
\text { samples }\end{array}$ & $\begin{array}{l}\text { Sample } \\
\text { shares }\end{array}$ \\
\hline Sample size & 1994 & $100 \%$ \\
\hline \multicolumn{3}{|l|}{ Household structure } \\
\hline Single & 393 & $19.7 \%$ \\
\hline Single living with parents & 359 & $18.0 \%$ \\
\hline Couple & 578 & $29.0 \%$ \\
\hline Couple living with children & 586 & $29.4 \%$ \\
\hline $\begin{array}{l}\text { Three generations living under one } \\
\text { roof }\end{array}$ & 78 & $3.9 \%$ \\
\hline \multicolumn{3}{|l|}{ Household income (Chinese Yuan) } \\
\hline$<50,000$ & 586 & $29.4 \%$ \\
\hline $50,000-100,000$ & 923 & $46.3 \%$ \\
\hline $100,000-150,000$ & 303 & $15.2 \%$ \\
\hline $150,000-200,000$ & 118 & $5.9 \%$ \\
\hline$>200,000$ & 64 & $3.2 \%$ \\
\hline \multicolumn{3}{|l|}{ Car ownership } \\
\hline 0 & 774 & $38.8 \%$ \\
\hline 1 & 1025 & $51.4 \%$ \\
\hline$\geq 2$ & 195 & $9.8 \%$ \\
\hline \multicolumn{3}{|l|}{ Commuting mode } \\
\hline Car & 253 & $12.7 \%$ \\
\hline Rail transit & 879 & $44.1 \%$ \\
\hline Bus & 626 & $31.4 \%$ \\
\hline Taxi & 66 & $3.3 \%$ \\
\hline Walk/bicycle & 150 & $7.5 \%$ \\
\hline Others & 20 & $1.0 \%$ \\
\hline \multicolumn{3}{|l|}{ Clustered decision sequence } \\
\hline Residence first & 1242 & $62.2 \%$ \\
\hline Workplace first & 752 & $37.8 \%$ \\
\hline
\end{tabular}

\section{Estimation Results and Elasticity Effects Analyses}

6.1. Estimation Results. Estimations of the above models were implemented with maximum simulated likelihood (MSL) method proposed by Bhat and Guo [10]. Randomly scrambled Halton method in Bhat [21] was used to achieve the random draws for MSL estimation.

The MSL estimations in this paper were carried out based on the GAUSS platform. Since the scrambled Halton sequence has been coded using GAUSS language and proved very efficient in Bhat [21], we simply borrowed the code and integrated it into the MSL estimation.

The estimated mean values of all the coefficients of five models are reported in Table 2, respectively.

In Table 2, the $t$-statistics are also presented in parentheses to show the significance of all explanatory variables. For unfixed parameters, mean values and standard deviations are both reported.
The residence location and workplace choice models without decision sequence are estimated as though all households in the sample choose location independently, based on all sample data. The residence location and workplace choice models with decision sequence are estimated as though some households in the sample choose residence conditional on a prior choice of workplace, while other households choose workplace conditional on a prior choice of residence, based on the clustered two groups of data, respectively. The joint residence-workplace location choice model is estimated as though residence and workplace influence each other, and all households in the sample consider the choice of two locations simultaneously.

From Table 2 we can find out that the signs and significances of all estimated parameters are generally consistent with prior expectations.

For common parameters in both residence and workplace choice models, the travel time, travel distance, and travel cost between residence location and workplace have expected negative signs, indicating that proximity to employment location is an important factor in residential location choice, and proximity to residence location is also an important factor in workplace choice.

For specific parameters in residence location choice models, the housing price has the expected negative sign, indicating that households tend to reside in area with low housing price under other fixed conditions. The positive sign of zonal population shows that households are more likely to locate in zones with high population, which reflects the population clustering effect. The number of rail transit stations has the expected positive sign; that is, households tend to live in zones with good accessibility to activity opportunities. The negative sign of FAR shows that households are also more likely to locate in zones with low residential density and comfortable community environment.

For particular parameters in workplace choice models, the household income has the expected positive sign; that is, households tend to choose the workplace which brings high income to them. The positive sign of employment opportunities shows that the number of available jobs is a rather important factor influencing the workplace choice. The gross sale of consumer goods also has the expected positive sigh, indicating that households are more likely to work in those zones with good shopping environment.

To further observe the parameters of single choice models, one can find out that, for all models, the magnitudes of travel distance and number of rail transit stations are both much bigger than other parameters. It shows that these two factors are much more important for household location choices. Further comparison between choices with and without decision sequence indicates that there is a modest improvement in the log-likelihood of the model with decision sequence, which underlines the significance of identifying the sequence of choosing residence and workplace locations.

For the joint residence-workplace location choice model, the basic pattern of results is consistent with the residence location choice models without and with decision sequence, and the estimated parameters are also rather significant from $t$-statistics. The travel distance and number of rail transit 
TABLE 2: Estimation results of five models.

\begin{tabular}{|c|c|c|c|c|c|}
\hline \multirow{2}{*}{ Variables } & \multicolumn{2}{|c|}{ Residence location choice } & \multicolumn{2}{|c|}{ Workplace choice } & \multirow{2}{*}{ Joint choice } \\
\hline & Without d-s & With d-s & Without d-s & With d-s & \\
\hline $\begin{array}{l}\text { Travel time } \\
\text { (M) }\end{array}$ & $\begin{array}{c}-0.2869 \\
(-7.89)\end{array}$ & $\begin{array}{c}-0.2962 \\
(-7.92)\end{array}$ & $\begin{array}{l}-0.1352 \\
(-21.55)\end{array}$ & $\begin{array}{l}-0.1134 \\
(-17.03)\end{array}$ & $\begin{array}{l}-0.3011 \\
(-6.88)\end{array}$ \\
\hline $\begin{array}{l}\text { Travel time } \\
\text { (S.D.) }\end{array}$ & $\begin{array}{c}0.3752 \\
(7.41)\end{array}$ & $\begin{array}{l}0.3921 \\
(8.09)\end{array}$ & $\begin{array}{l}0.0517 \\
(6.29)\end{array}$ & $\begin{array}{c}0.0604 \\
(7.36)\end{array}$ & $\begin{array}{c}0.2744 \\
(8.11)\end{array}$ \\
\hline $\begin{array}{l}\text { Travel distance } \\
\text { (M) }\end{array}$ & $\begin{array}{l}-0.8255 \\
(-8.76)\end{array}$ & $\begin{array}{c}-0.8403 \\
(-8.92)\end{array}$ & $\begin{array}{l}-0.4948 \\
(-23.88)\end{array}$ & $\begin{array}{l}-0.4706 \\
(-19.85)\end{array}$ & $\begin{array}{c}-0.6602 \\
(-8.95)\end{array}$ \\
\hline $\begin{array}{l}\text { Travel distance } \\
\text { (S.D.) }\end{array}$ & $\begin{array}{c}0.4385 \\
(7.42)\end{array}$ & $\begin{array}{c}0.5035 \\
(7.95)\end{array}$ & $\begin{array}{c}0.1071 \\
(7.38)\end{array}$ & $\begin{array}{l}0.2251 \\
(5.66)\end{array}$ & $\begin{array}{c}0.3849 \\
(6.77)\end{array}$ \\
\hline Travel cost & $\begin{array}{l}-0.1233 \\
(-5.04)\end{array}$ & $\begin{array}{l}-0.1022 \\
(-4.47)\end{array}$ & $\begin{array}{l}-0.0323 \\
(-11.55)\end{array}$ & $\begin{array}{l}-0.0396 \\
(-10.34)\end{array}$ & $\begin{array}{c}-0.0371 \\
(-4.61)\end{array}$ \\
\hline Housing price & $\begin{array}{c}-0.2363 \\
(-3.22)\end{array}$ & $\begin{array}{c}-0.4623 \\
(-6.47)\end{array}$ & 1 & 1 & $\begin{array}{c}-0.4437 \\
(-4.78)\end{array}$ \\
\hline Population & $\begin{array}{l}0.0417 \\
(3.25)\end{array}$ & $\begin{array}{c}0.0217 \\
(2.01)\end{array}$ & 1 & 1 & $\begin{array}{c}0.0214 \\
(2.14)\end{array}$ \\
\hline Number of rail transit stations & $\begin{array}{c}0.4449 \\
(4.22)\end{array}$ & $\begin{array}{l}0.5012 \\
(5.66)\end{array}$ & 1 & 1 & $\begin{array}{c}0.3706 \\
(3.21)\end{array}$ \\
\hline FAR & $\begin{array}{c}-0.0388 \\
(-1.99)\end{array}$ & $\begin{array}{c}-0.0488 \\
(-2.93)\end{array}$ & 1 & 1 & $\begin{array}{l}-0.0841 \\
(-2.07)\end{array}$ \\
\hline Household income & 1 & 1 & $\begin{array}{c}0.2624 \\
(3.88)\end{array}$ & $\begin{array}{c}0.4607 \\
(5.25)\end{array}$ & $\begin{array}{c}0.3329 \\
(4.16)\end{array}$ \\
\hline Employment opportunities & 1 & 1 & $\begin{array}{c}0.0224 \\
(5.24)\end{array}$ & $\begin{array}{l}0.0274 \\
(6.44)\end{array}$ & $\begin{array}{l}0.0271 \\
(4.21)\end{array}$ \\
\hline Gross sale & 1 & 1 & $\begin{array}{l}0.1122 \\
(2.01)\end{array}$ & $\begin{array}{c}0.2101 \\
(3.11)\end{array}$ & $\begin{array}{c}0.0866 \\
(3.71)\end{array}$ \\
\hline Number of observations & 1994 & 752 & 1994 & 1242 & 1994 \\
\hline log-likelihood at convergence & -1304 & -1263 & -1279 & -1154 & -1089 \\
\hline
\end{tabular}

Here d-s means "decision sequence"; M means "mean value"; S.D. means "standard deviation."

stations are again significant and in the expected direction, with the same pattern of relatively larger magnitude than other parameters. The negative sign of the travel distance indicates that the shorter the travel distance between residence location and workplace, the more the likelihood of the zone being chosen as the residence location.

Again, the pattern of estimation results of the joint choice model is generally consistent with the workplace choice models without and with decision sequence, and also the estimated parameters are rather significant from $t$-statistics. The largest magnitude of travel distance again shows its importance for the workplace choice.

From the log-likelihood at convergence, we can further find out that the index of the joint choice model is the largest among all five models. It means that the joint choice of residence location and workplace is the most similar to household natural choice behavior mechanism.

6.2. Elasticity Effect Analyses. Since the coefficients in a complex choice models are not straightforward to understand, we further implement three groups of elasticity effects analyses for the joint choice model. To extract the different characteristics between urban and suburban households, the choice alternatives are classified into two groups: urban area and suburban area.

The following explanatory variables are used.

(1) Number of Rail Transit Stations. Seven scenarios are developed based on the number of rail transit stations: $-50 \%$, $-30 \%,-10 \%$, base $0 \%,+10 \%,+30 \%$, and $+50 \%$. The choice probabilities of 7 scenarios are shown in Figure 1.

Figure 1 shows that, with the same number of rail transit stations, the choice probability in suburban area is higher than that in urban area. With the decrease of the number of rail transit stations, the choice probability of suburban area decreases more dramatically than that of urban area. All these show that suburban households pay more attention to rail transit than urban households.

(2) Housing Price. Seven scenarios are also developed based on the housing price: $-50 \%,-30 \%,-10 \%$, base $0 \%,+10 \%$, $+30 \%$, and $+50 \%$. The choice probabilities of 7 scenarios are shown in Figure 2.

With the increase of housing price, the choice probability of suburban area drops more sharply than that of urban area. It means that suburban households are more sensitive to housing price. 


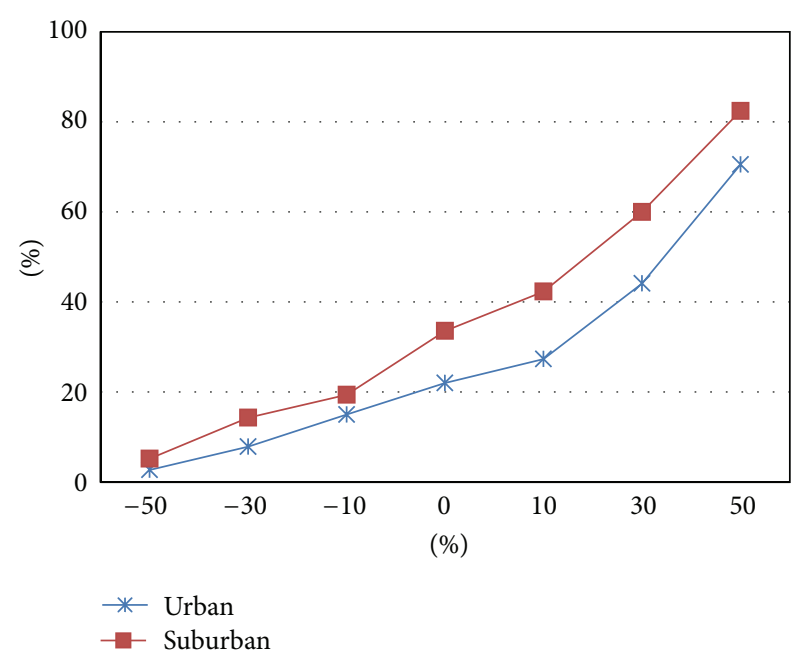

FIGURE 1: Elasticity effect based on number of rail transit stations.

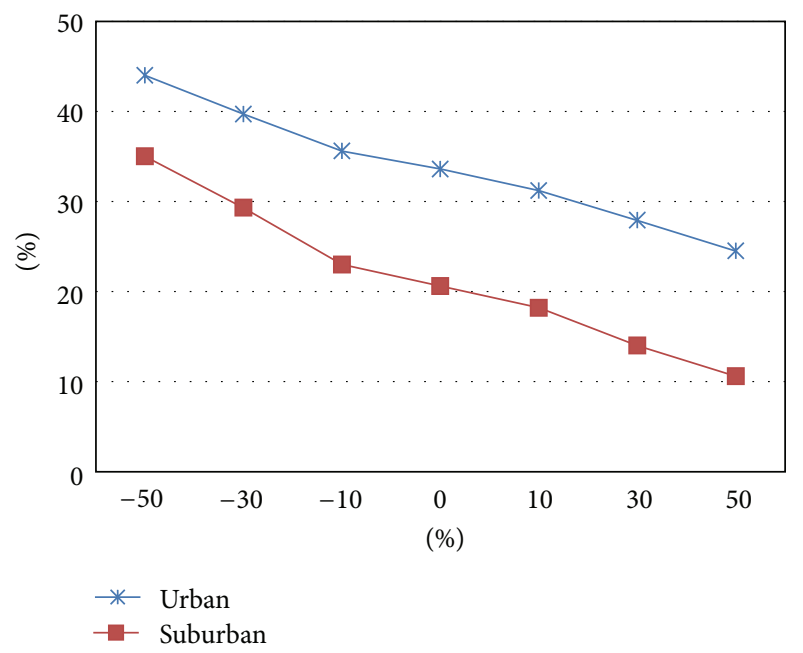

FIgURE 2: Elasticity effect based on housing price.

(3) Household Income. Seven scenarios are further developed based on the household income: $-50 \%,-30 \%,-10 \%$, base $0 \%,+10 \%,+30 \%$, and $+50 \%$. The choice probabilities of 7 scenarios are shown in Figure 3.

Comparing with the above two variables, the household income is the most sensitive index. Obviously, with the increase of household income, the choice probability of urban area rises more dramatically than that of suburban area. It shows that households tend to live and work in urban area to improve their income.

\section{Conclusions}

This paper addresses five mixed logit models concerning location choices: residence location choice model without decision sequence, residence location choice model with decision sequence, workplace choice model without decision sequence, workplace choice model with decision sequence, and the joint residence-workplace location choice model. We

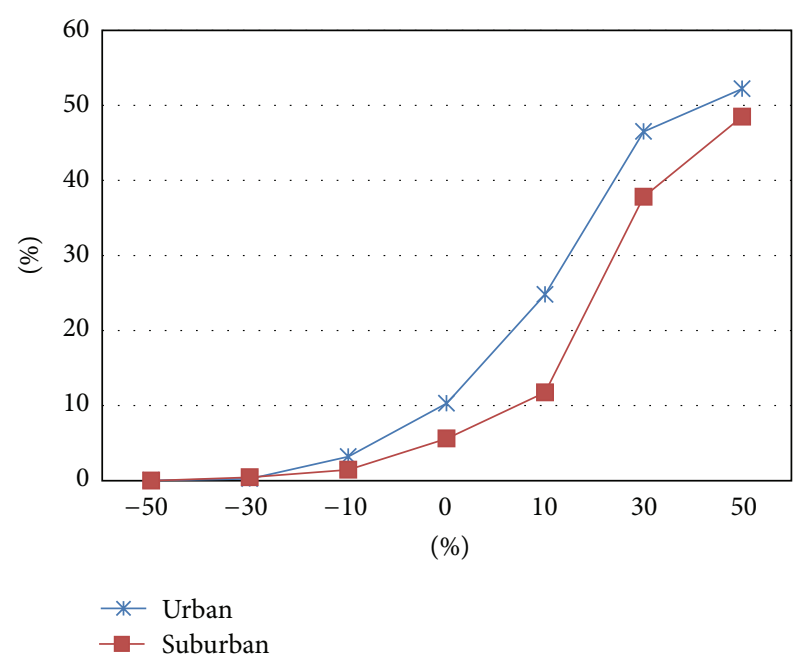

FIGURE 3: Elasticity effect based on household income.

first assume that residence and workplace choice behaviors are independent of each other and formulate two basic choice models without decision sequence. Then we cluster households into two groups, choosing residence or workplace first, and propose two choice models with decision sequence; that is, residence location choice is conditional on predetermined workplace, or vice versa. We further put forward a joint choice model to combine the residence location and workplace together. A questionnaire survey is implemented in Beijing city to collect the data of 1994 households. Estimated parameters show that the travel distance and number of rail transit stations are the most important two factors for household location choices. The log-likelihood at convergence indicates that choice models with decision sequence are much more significant than models without decision sequence, and the joint choice model is the most reasonable. Further elasticity effects analyses show that the joint choice model reflects the influences of relevant factors to the choice probability very well.

This research is further directed towards two aspects. The first is to take into account the differences among male, female, and children and to model the choice behaviors of households with different family structures. The second is to capture the dynamics of household residence location and workplace changes using panel data.

\section{Conflict of Interests}

The authors declare that there is no conflict of interests regarding the publication of this paper.

\section{Acknowledgments}

The research herein reported has been supported by National Natural Science Foundation of China Project (51208024), Science and Technology Project of Ministry of Housing and Urban-Rural Development of China (2013-K5-6), Beijing Philosophy and Social Science Project (14CSC014), Excellent 
Talents Project of Beijing Municipal Committee Department of Organization (2013D005017000001), and the Importation and Development of High-Caliber Talents Project of Beijing Municipal Institutions (CIT\&TCD201404071).

\section{References}

[1] S. R. Lerman, "Location, housing, automobile ownership and mode to work: a joint choice model," Transportation Research Record, no. 610, pp. 6-11, 1976.

[2] D. McFadden, "Modeling the choice of residential location," Transportation Research Record, no. 672, pp. 72-77, 1978.

[3] H. Timmermans, A. Borgers, J. van Dijk, and H. Oppewal, "Residential choice behaviour of dual earner households: a decompositional joint choice model," Environment and Planning A, vol. 24, no. 4, pp. 517-533, 1992.

[4] P. Waddell, "Exogenous workplace choice in residential location models: is the assumption valid?" Geographical Analysis, vol. 25, no. 1, pp. 65-82, 1993.

[5] P. Waddell, "Accessibility and residential location: the interaction of workplace, residential mobility, tenure, and location choices," in Proceedings of the Lincoln Land Institute TRED Conference, 1996.

[6] M. E. Ben-Akiva and J. L. Bowman, "Integration of an activitybased model system and a residential location model," Urban Studies, vol. 35, no. 7, pp. 1131-1153, 1998.

[7] M. W. Sermons and F. S. Koppelman, "Factor analytic approach to incorporating systematic taste variation into models of residential location choice," Transportation Research Record, no. 1617, pp. 194-202, 1998.

[8] M. W. Sermons, "Influence of race on household residential utility," Geographical Analysis, vol. 32, no. 3, pp. 225-246, 2000.

[9] M. W. Sermons and F. S. Koppelman, "Representing the differences between female and male commute behavior in residential location choice models," Journal of Transport Geography, vol. 9, no. 2, pp. 101-110, 2001.

[10] C. R. Bhat and J. Guo, "A mixed spatially correlated logit model: formulation and application to residential choice modeling," Transportation Research B, vol. 38, no. 2, pp. 147-168, 2004.

[11] K. Miyamoto, V. Vichiensan, N. Shimomura, and A. Páez, "Discrete choice model with structuralized spatial effects for location analysis," Transportation Research Record, no. 1898, pp. 183-190, 2004.

[12] C. R. Bhat and J. Y. Guo, "A comprehensive analysis of built environment characteristics on household residential choice and auto ownership levels," Transportation Research B, vol. 41, no. 5, pp. 506-526, 2007.

[13] J. Y. Guo and C. R. Bhat, "Operationalizing the concept of neighborhood: application to residential location choice analysis," Journal of Transport Geography, vol. 15, no. 1, pp. 31-45, 2007.

[14] P. Jiao and N. Harata, "Residential location choice for different households: methodology and case study," Journal of the Eastern Asia Society for Transportation Studies, vol. 7, pp. 1280-1295, 2007.

[15] X. Li, C. Zhuge, X. Zhang, J. Gao, and H. Zhang, "Multiobjective optimization model of residential spatial distribution," Mathematical Problems in Engineering, vol. 2014, Article ID 167495, 9 pages, 2014.

[16] J. E. Abraham and J. D. Hunt, "Specification and estimation of nested logit model of home, workplaces, and commuter mode choices by multiple-worker households," Transportation Research Record, no. 1606, pp. 17-24, 1997.

[17] J. Levine, "Rethinking accessibility and jobs-housing balance," Journal of the American Planning Association, vol. 64, no. 2, pp. 133-149, 1998.

[18] P. Waddell, C. R. Bhat, N. Eluru, L. Wang, and R. M. Pendyala, "Modeling interdependence in household residence and workplace choices," Transportation Research Record, no. 2003, pp. 84-92, 2007.

[19] X. Li, C. Shao, and L. Yang, "Simultaneous estimation of residential, workplace location and travel mode choice based on nested logit model," in Proceeding of the 7th International Conference on Fuzzy Systems and Knowledge Discovery (FSKD '10), vol. 4, pp. 1725-1729, Yantai, China, August 2010.

[20] Á. Ibeas, R. Cordera, L. Dell'Olio, and P. Coppola, "Modelling the spatial interactions between workplace and residential location," Transportation Research A: Policy and Practice, vol. 49, pp. 110-122, 2013.

[21] C. R. Bhat, "Simulation estimation of mixed discrete choice models using randomized and scrambled Halton sequences," Transportation Research B: Methodological, vol. 37, no. 9, pp. 837-855, 2003. 


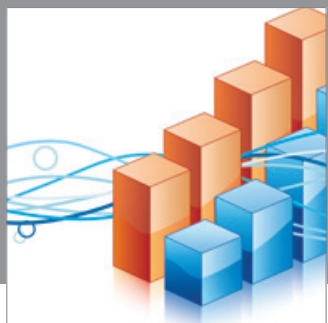

Advances in

Operations Research

mansans

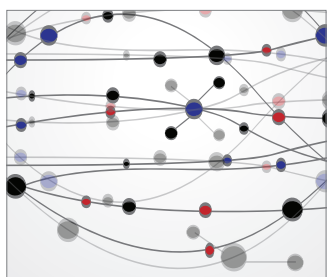

The Scientific World Journal
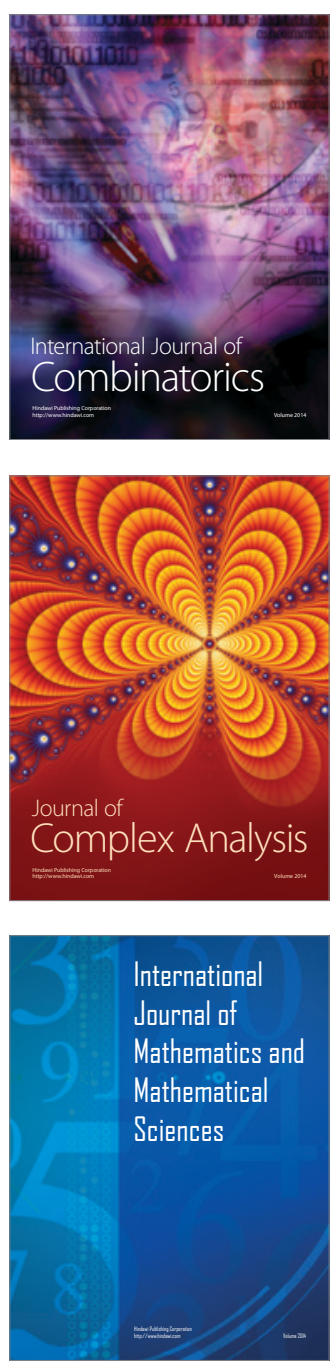
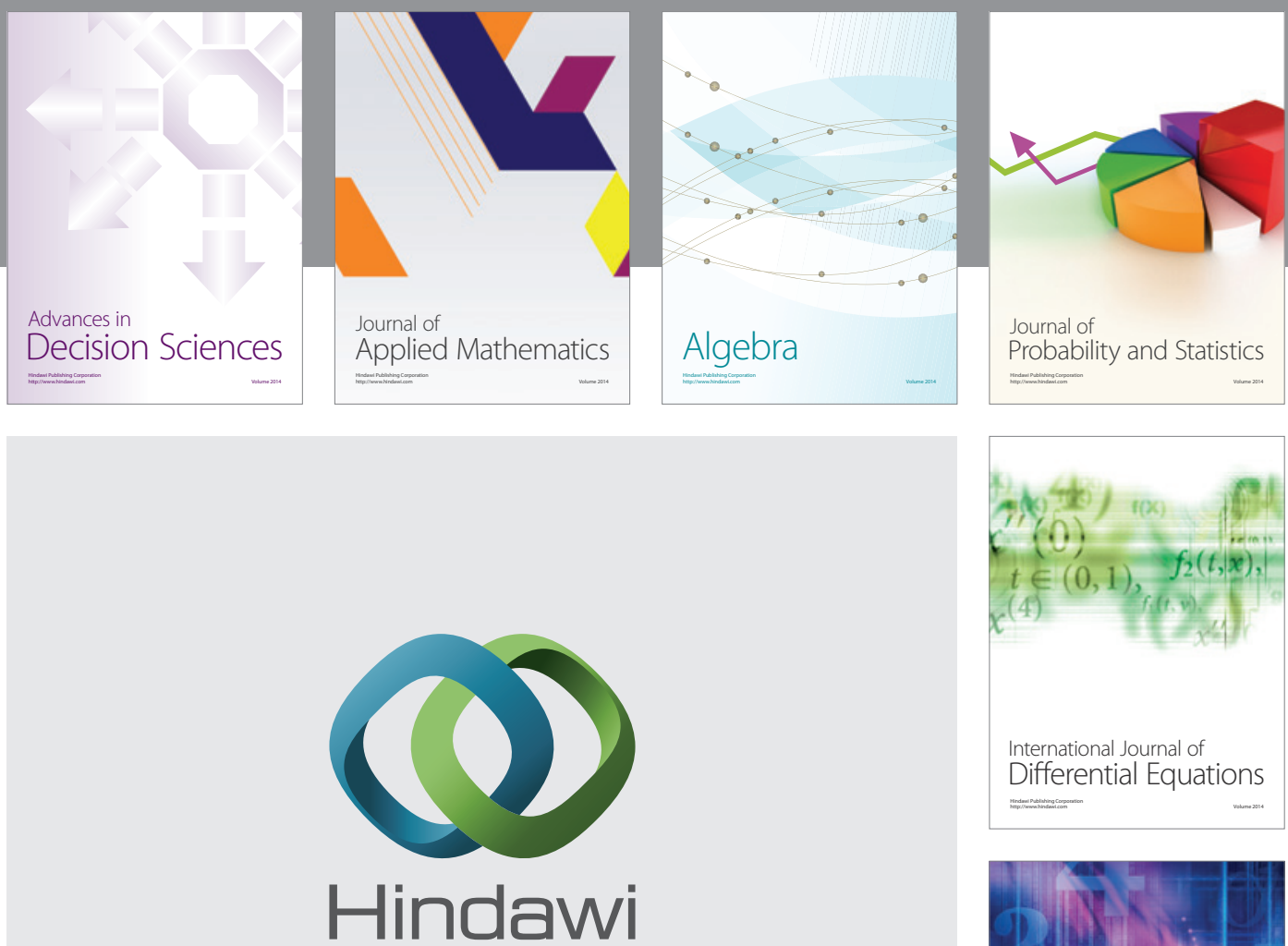

Submit your manuscripts at http://www.hindawi.com
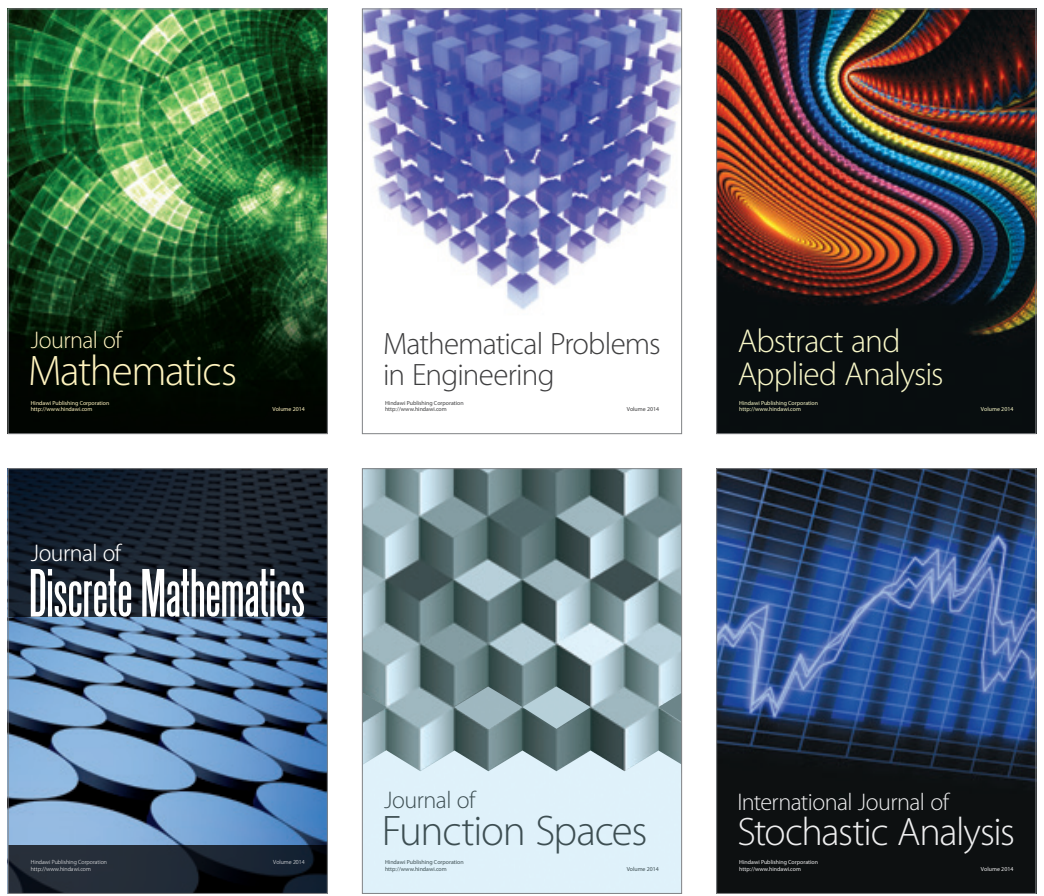

Journal of

Function Spaces

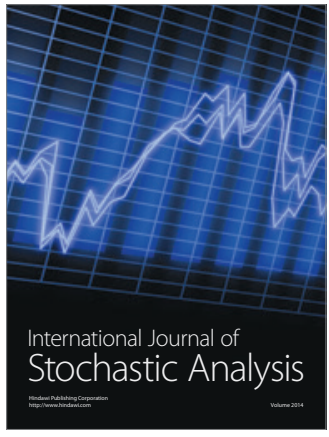

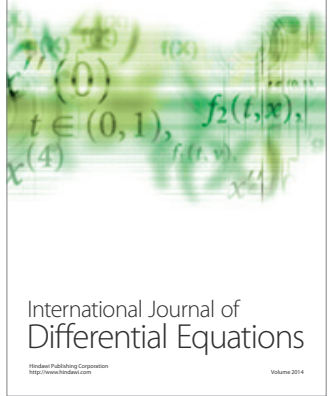
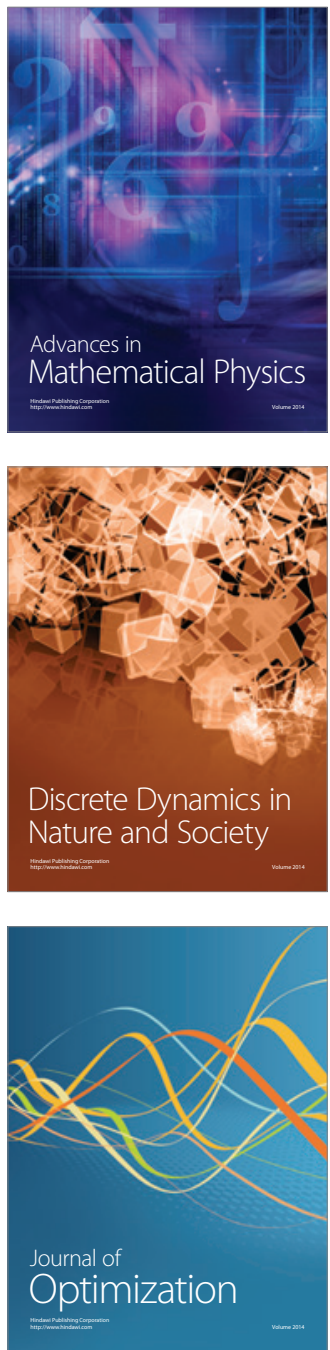